\title{
ANÁLISIS DE LAS IMPLICACIONES LEGISLATIVAS PENALES DE LAS MEDIDAS ADOPTADAS EN EL PACTO DE ESTADO CONTRA LA VIOLENCIA DE GÉNERO
}

\author{
Bárbara ROMO SABANDO \\ PROFESORA ASOCIADA \\ UNIVERSIDAD DE LA RIOJA
}

SUMARIO: Estado de la cuestión. A) Primer grupo: Medidas relativas a las circunstancias modificativas de la responsabilidad penal. B) Segundo grupo: Medidas relativas a las penas y medidas. C) Tercer grupo: Medidas relativas al delito de quebrantamiento. D) Cuarto grupo: Medidas que hacen referencia a delitos concretos dentro de la parte especial del Código penal. Conclusiones. Bibliografía.

RESUMEN: El Pacto de Estado contra la Violencia de Género aprobado en 2017 ha recopilado múltiples medidas que implican modificaciones a realizar en diferentes ámbitos por parte de la administración. En este trabajo se han analizado dichas medidas para extraer aquellas que conllevan una modificación legislativa a nivel penal, estableciendo en primer lugar una clasificación sistemática de las mismas, para posteriormente realizar un análisis de cada una de ellas, estableciendo la idoneidad de cada una de las reformas propuestas, analizando las razones de política criminal que las impulsan, y las dificultades que las mismas pueden encontrar en su encaje legal.

Palabras Clave: violencia de género, medidas, política criminal.

ABSTRACT: The State Pact against Gender Violence approved in 2017 has compiled multiple measures that imply modifications to be made in different areas by the administration. In this article, these measures have been analyzed to extract those that entail a legislative modification at the penal level, establishing first a systematic classification of them, to later carry out an analysis of each of them, establishing the suitability of each one of the proposed reforms, analyzing the reasons for criminal policy that drive them, and the difficulties that they can find in their legal reserve.

KEYWORDS: gender violence, measures, criminal policy.

\section{Estado de la cuestión}

A lo largo de las últimas dos décadas se han llevado a cabo múltiples revisiones en la legislación española con el fin de adecuar la respuesta normativa a un problema social que había permanecido en el ámbito privado del hogar.

Las continuas agresiones a los bienes jurídicos básicos hacia las mujeres en el marco conyugal, quedaban en muchas ocasiones sin respuesta ante la pasividad de las 
autoridades, que interpretaban la infracción penal como un problema doméstico que no precisaba de respuesta por parte de la administración.

El intento de establecer una protección eficiente por parte del legislador español da como resultado una elaboración normativa que modifica sustancialmente en el código penal, con la promulgación de la Ley Orgánica I/2004, de 28 de diciembre, de Medidas de Protección Integral contra la Violencia de Género.

Tras una década de aplicación de la Ley Integral contra la Violencia de Género, y pese a la aprobación de normativa posterior relacionada con las víctimas ${ }^{\mathrm{I}}$, se valora la necesidad de elaborar un Pacto en materia de violencia de Género, que cubra las necesidades detectadas en la puesta en práctica de la normativa de referencia. El documento final elaborado se expresaba en los siguientes términos:

El Pleno del Congreso de los Diputados aprobó por unanimidad, en su sesión del día i5 de noviembre de 20I6, una Proposición no de Ley por la que se instaba al Gobierno a promover la suscripción de un Pacto de Estado en materia de Violencia de Género por el Gobierno de la Nación, las Comunidades Autónomas y Ciudades con Estatuto de Autonomía y la Federación Española de Municipios y Provincias, que siguiese impulsando políticas para la erradicación de la violencia sobre la mujer como una verdadera política de Estado. Un pacto que recuperase el espíritu de consenso de la Ley Orgánica I/2004, de 28 de diciembre, de medidas de protección integral contra la violencia de género, vinculando a todos los partidos políticos, poderes del Estado y sociedad civil, en un compromiso firme en pro de una política sostenida para la erradicación de la violencia de género

La Proposición no de Ley establecía la creación, en el seno de la Comisión de Igualdad del Congreso, de una Subcomisión que tuviese como objetivo elaborar un informe con el fin de identificar y analizar los problemas que impiden avanzar en la erradicación de las diferentes formas de violencia de género. Dicho informe debería incluir un conjunto de propuestas de actuación, entre ellas las principales reformas que deben acometerse para dar cumplimiento efectivo a ese fin, así como a las recomendaciones de los organismos internacionales, ONU y Convenio de Estambul.

Ante esta Subcomisión comparecieron 66 expertas y expertos en materia de violencia sobre las mujeres. Por su parte, la Comisión de Igualdad del Senado decidió, el 2I de diciembre de 2016, la creación de una Ponencia que estudiase y evaluase, en materia de Violencia de Género, los aspectos de prevención, protección y reparación de las víctimas, analizase la estrategia para alcanzar e implementar un Pacto de Estado contra la Violencia de Género y examinase la Ley Orgánica I/2004, de 28 de diciembre, de Medidas de Protección Integral contra la Violencia de Género. Ante esta Ponencia comparecieron un total de 52 personas expertas en materia de violencia contra las mujeres. Documento refundido de medidas del Pacto de Estado en materia de Violencia de Género.

${ }^{\mathrm{I}}$ Ley 4/2015, de 27 de abril, del Estatuto de la víctima, del Real Decreto IIo9/20I5, de II de diciembre, por el que se desarrolla la Ley 4/20I5, de 27 de abril, del Estatuto de la víctima del delito, y se regulan las Oficinas de Asistencia a las Víctimas del Delito, y la reforma llevada a cabo por Ley Orgánica I/20I5, de 30 de marzo, por la que se modifica la Ley Orgánica Io/1995, de 23 de noviembre, del Código Penal. 
Asimismo, la sexta Conferencia de Presidentes, reunida el I7 de enero de 20I7, adoptó el acuerdo de convocar la Comisión General de las CCAA del Senado para debatir las aportaciones de las Comunidades Autónomas al Pacto de Estado. En cumplimiento de este Acuerdo, el 9 de marzo de 2017 se celebró, en el seno de la Comisión General de las Comunidades Autónomas del Senado, una comparecencia de la Ministra de Sanidad, Servicios Sociales e Igualdad, para dar cuenta del acuerdo sobre un pacto de Estado contra la Violencia de Género. En el debate participaron representantes de las diferentes Comunidades Autónomas. Tras este debate monográfico, el Pleno del Senado, en su sesión celebrada el día 5 de abril de 20I7, aprobó la moción número 5I, de la Comisión General de las Comunidades Autónomas, mediante la cual el Senado se mostró favorable a alcanzar un Pacto de Estado contra la Violencia de Género, y formuló una serie de propuestas para que fueran incorporadas al mencionado Pacto. Estas propuestas se trasladaron a la Subcomisión del Congreso y a la Ponencia del Senado. Paralelamente a los trabajos desarrollados en el ámbito Parlamentario, en el seno del Observatorio Estatal de Violencia sobre la Mujer se propuso y consensuó la constitución de un Grupo de Trabajo con el objetivo de facilitar la reflexión y recopilar las aportaciones de todas las entidades representadas en el mismo. Con el fin de que el documento recogiera todas las sensibilidades y propuestas, el Grupo de Trabajo se abrió a la participación no solo de los miembros del Observatorio Estatal de Violencia sobre la Mujer, sino de todas las Comunidades Autónomas y organizaciones especializadas de la sociedad civil, sumando finalmente 46 entidades participantes.

Como conclusión de los trabajos de este Grupo se elaboró un documento en el que se recogieron todas las medidas de las entidades participantes para mejorar la atención a las mujeres víctimas de violencia de género y sus hijos e hijas menores. Este documento se remitió al Congreso y Senado para su toma en consideración. Tras varios meses de trabajos, el I3 de septiembre de 2017 el Pleno del Senado aprobó, por unanimidad, el Informe de la Ponencia de Estudio para la elaboración de estrategias contra la violencia de género.

Por su parte, el Congreso, en su sesión plenaria del 28 de septiembre de 20I7, aprobó sin ningún voto en contra el Informe de la Subcomisión para un Pacto de Estado en materia de Violencia de Género.

Ambos informes, tras identificar la situación en la que se encuentra actualmente la lucha contra la violencia de género en nuestro país y analizar los problemas que impiden avanzar en la erradicación de las diferentes formas de dicha violencia, recogen un conjunto de propuestas de actuación para los próximos años entre las que se incluyen específicamente las principales reformas que deben acometerse para dar cumplimiento efectivo a ese fin, así como a las recomendaciones de los organismos internacionales, Naciones Unidas y Consejo de Europa. Los dos textos, como indicaba la Proposición No de Ley, se remitieron al Gobierno para que los sometiera a acuerdo con los representantes de Comunidades Autónomas, ayuntamientos, partidos políticos, Administración de Justicia, organizaciones sindicales y empresariales y asociaciones civiles. ${ }^{2}$

\footnotetext{
${ }^{2}$ Documento refundido de medidas del pacto de estado en materia de violencia de género. Congreso + Senado.
} 
Finalmente, se llevó a cabo la elaboración de un texto refundido con las medidas adoptadas en ambas Cámaras, que contiene 292 medidas para acometer en distintos ámbitos.

Dentro de esas 292 medidas que recoge el texto refundido, he llevado a cabo un análisis exhaustivo de las mismas con la finalidad de identificar aquellas que implican una modificación en el actual Código penal; tras la realización del análisis he determinado que I4 medidas pueden ser consideras susceptibles de impulsar dicha modificación legislativa.

Una vez identificadas las medidas descritas en el documento refundido elaborado por el Parlamento, tras analizar las mismas, se ha llevado a cabo un proceso de clasificación, que facilita el análisis de las mismas.

Se crea la siguiente clasificación en función de la materia abordada por cada una de las medidas:

- Primer grupo: medidas relativas a las circunstancias modificativas de la responsabilidad penal.

- Segundo grupo: medidas relativas a las penas y medidas.

- Tercer grupo: medidas relacionas con el delito de quebrantamiento.

- Cuarto grupo: medidas que hacen referencia a delitos concretos dentro de la parte especial del Código penal.

\section{A) Primer grupo: Medidas relativas a las circunstancias modificativas de la responsabilidad penal}

Medida 106-Suprimir la atenuante de confesión en delitos de violencia de género, cuando las circunstancias de los hechos permitan atribuir fehacientemente su autoría, siempre que se respeten los estándares de constitucionalidad en relación con el principio de igualdad.

Tanto la doctrina como la jurisprudencia fundamentan esta atenuante en consideraciones de política criminal, en las que se premia actuaciones posteriores al delito que supongan una colaboración relevante en la indagación del hecho delictivo ${ }^{3}$.

La jurisprudencia actual muestra que cada vez se ha ido aplicando en más procedimientos por homicidio y asesinatos en el ámbito de la violencia de género dicha circunstancia modificativa de la responsabilidad penal, sin que en la investigación de esos casos se haya evidenciado una agilización en el proceso que vaya unida a la confesión de la comisión del delito.

No se valora apropiado la supresión de dicha circunstancia modificativa de la responsabilidad penal para los delitos relacionados con violencia de género; carece de sentido eliminar la misma atendiendo al tipo de delito, cuando parece que la finalidad que se persigue a tenor de lo anterior es fundamentar la relevancia de la colaboración en la investigación, por lo que sí se valora conveniente rescatar la interpretación teleológica de la misma, que no permita una aplicación sistemática en este tipo de delitos.

\footnotetext{
${ }_{3}^{3}$ Solaz Solaz, «La circunstancia atenuante de confesión», La Ley Digital, n Iı3,2005, p. 8.
} 
Medida 107-Suprimir la atenuante de reparación del daño en los casos de violencia de género.

La atenuante de reparación del daño ocasionado a la víctima, o de disminución de sus efectos, constituye una manifestación más de la moderna política criminal configuradora de un Derecho penal orientado a las víctimas, que alcanza su máxima expresión con la aprobación de Ley 4/2015, de 27 de abril, del Estatuto de la víctima. Se trata con ello de procurar a ayuda a las víctimas, de incentivar la reparación, desde el punto de vista de una política criminal orientada a potenciar los nuevos criterios derivados de las modernas corrientes victimológicas ${ }^{4}$.

Respecto del art.2I.5 del Código Penal ya se pronunció el Tribunal Supremo en Sentencia 664/2014, de 7 de octubre, donde se establecía que para que dicha atenuante pueda ser aplicada es necesario que la «reparación ha de ser suficientemente significativa y relevante, y puede llevarse a cabo a través de la restitución, de la indemnización de los perjuicios, de la reparación moral o incluso de la reparación simbólica».

Suprimirla supondría una contradicción con el espíritu reparador y la apuesta por la justicia restaurativa que recoge la Ley 4/2015, de 27 de abril, del Estatuto de la víctima del delito, que también es lícita para los casos de violencia de género, salvaguardando claro está la prohibición de la mediación penal.

Medida 108- Generalizar la aplicación de la circunstancia agravante del artículo 22.4 del Código Penal para los casos de mutilación genital femenina.

En 2003 se plantea la reforma del Código penal desde el reconocimiento de que con la integración social de los extranjeros en España aparecen nuevas realidades a las que el ordenamiento debe dar adecuada respuesta. Así, como novedad igualmente reseñable, se tipifica el delito de mutilación genital o ablación. Y ello porque la mutilación genital de mujeres y niñas es una práctica que debe combatirse con la máxima firmeza, sin que pueda en absoluto justificarse por razones pretendidamente religiosas o culturales. Esta reforma ya había sido planteada en el seno de las Cortes a través de una proposición de ley que pretendía introducir una cláusula interpretativa sobre la represión de la mutilación genital femenina ${ }^{5}$.

Atendiendo a la regulación expresa que se recoge el art. I49.2 $\mathrm{Cp}^{6}$, y en concreto a la exposición de motivos que recoge la reforma del texto legal en 2003 , se podría entender que el elemento subjetivo de desvalor de la acción queda recogido en el tipo, por lo que aplicar la circunstancia modificativa de la responsabilidad penal recogida en el art.22.4 Cp, cometer el delito por razones de género, podría suponer la violación del principio non bis in ídem.

\footnotetext{
${ }^{4}$ «La circunstancia atenuante de la reparación del daño», La ley penal, $\mathrm{n}^{\circ} 44$, Sección monografías de Jurisprudencia, Diciembre 2007.

${ }^{5}$ Exposición de motivos IV. Ley Orgánica II/2003, de 29 de septiembre, de medidas concretas en materia de seguridad ciudadana, violencia doméstica e integración social de los extranjeros.

${ }^{6}$ Artículo I49. 2. El que causara a otro una mutilación genital en cualquiera de sus manifestaciones será castigado con la pena de prisión de seis a i2 años. Si la víctima fuera menor o persona con discapacidad necesitada de especial protección, será aplicable la pena de inhabilitación especial para el ejercicio de la patria potestad, tutela, curatela, guarda o acogimiento por tiempo de cuatro a io años, si el juez lo estima adecuado al interés del menor o persona con discapacidad necesitada de especial protección.
} 
De la jurisprudencia constitucional en este caso se desprende que no es posible la aplicación conjunta de dos sanciones penales a un mismo hecho, puesto que, si ambas son penales, normalmente tendrán el mismo fundamento y, con toda seguridad, se impondrán ambas por autoridades del orden judicial, con lo que no podrán acumularse ${ }^{7}$.

No será aplicable la agravante de género en los casos en que las conductas enjuiciadas sean subsumibles en los tipos penales en los que ya está recogida, aún de forma implícita, la discriminación, la desigualdad o la relación de poder del hombre sobre la mujer ${ }^{8}$.

Por lo anteriormente puesto, no parece apropiada la aplicación de agravante genérica en el caso analizado, si bien cabría estudiar la implementación de circunstancias agravantes específicas atendiendo a una mayor lesividad de la que recogería el tipo básico.

Medida 110-Recomendar la aplicación de la circunstancia $4^{a}$ del artículo 22 del Código Penal, en todos los casos en los que resulte probado el elemento subjetivo de motivos machistas o discriminatorios hacia la mujer, o por razones de género, en los casos de agresión sexual y abuso sexual de los artículos 178 a 183 bis del Código Penal.

Es necesario en este punto establecer una diferenciación entre los conceptos sexo y género. El sexo viene determinado por la naturaleza, establecido por un criterio puramente biológico, mientras que el género proviene de una construcción psicológica a nivel individual, social y cultural a nivel supraindividual. La sociedad asigna roles como propios de hombres y de mujeres.

El Tribunal Constitucional 9 establece que

el término «género» que titula la Ley y que se utiliza en su articulado pretende comunicar y no se trata de una discriminación por razón de sexo. No es el sexo en sí de los sujetos activo y pasivo lo que el legislador toma en consideración con efectos agravatorios, sino -una vez más importa resaltarlo- el carácter especialmente lesivo de ciertos hechos a partir del ámbito relacional en el que se producen y del significado objetivo que adquieren como manifestación de una grave y arraigada desigualdad. La sanción no se impone por razón del sexo del sujeto activo ni de la víctima ni por razones vinculadas a su propia biología. Se trata de la sanción mayor de hechos más graves, que el legislador considera razonablemente que lo son por constituir una manifestación específicamente lesiva de violencia y de desigualdad.

Atendiendo a lo anteriormente expuesto, cabe la aplicación de la agravante del art.22.4 en los delitos recogidos en los artículos I78 a I83 bis del Código Penal, siempre que quede probado dicha manifestación de desigualdad que supere el ámbito de la protección de la indemnidad sexual, por lo que se descartaría la aplicación sistemática de la misma en los delitos anteriores.

\footnotetext{
${ }^{7}$ Muñoz Conde y García Arán, Derecho Penal. Parte General, Valencia, Tirant lo Blanch, 20I5, p. II9.

${ }^{8}$ Peramato Martín, «Modificaciones en el Código penal, Ley Orgánica I/20I5, de 30 de marzo, en materia de Violencia de Género», Boletín de la Comisión de violencia de género de Jueces para la Democracia, nº 2, 2016, p. 9.

${ }^{9}$ STC 59/2008, de I4 de mayo.
} 
No obstante, la prueba de la motivación no será sencilla, pues deberá acreditarse la concurrencia de un elemento subjetivo ${ }^{\text {IO }}$.

Medida 128-Modificación del Art 22.8 del Código Penal para considerar reincidencia cuando el mismo hombre cometiera distintos delitos contra la misma mujer. En consonancia con el Convenio de Estambul. Abriendo la posibilidad a incluir reincidencia si el mismo hombre comete distintos delitos de esta naturaleza contra distintas mujeres.

En relación con el fundamento de la agravante de reincidencia, se advierten importantes divergencias en la doctrina, cuestionándose incluso su constitucionalidad. Así, se señala, por un parte, un mayor contenido de culpabilidad, en la medida en que actor reincide. Mientras que otros muestran sus dudas sobre la constitucionalidad de esta circunstancia en el marco de un Derecho penal respetuoso del fuero interno y que quiera limitarse a proteger bienes jurídicos ${ }^{\mathrm{II}}$.

El hecho de que en un determinado momento el legislador optara por regular los delitos relativos a la violencia de género en diferentes Capítulos del código penal, nos sitúa en la paradoja de no poder aplicar esta agravante cuando se dan dos tipos delictivos distintos que protegen distintos bienes jurídicos, pero que se realizan sobre la misma persona. Este problema se encuentre relacionado con los delitos relativos a la violencia de género, pero también serían aplicables a los relacionados con la violencia doméstica.

Cabría valorar la posibilidad de interpretar el artículo 22.8 del Código penal, posibilitando la aplicación de la agravante en los delitos de misma naturaleza, independientemente de la ubicación que ocupen en la norma, argumentando la similitud del bien jurídico protegido, pese a que resulte contradictorio teniendo en cuenta las posturas doctrinales descritas en relación a este precepto.

\section{B) Segundo grupo: Medidas relativas a las penas y medidas}

Medida 114- Extender la pena accesoria de privación de tenencia y porte de armas no sólo al delito de lesiones como hasta ahora, sino también a las coacciones o amenazas.

El Código penal prevé como pena privativa de derechos, para el caso de amenazas leves en los casos de violencia de género, pero también para los sujetos del art.I73.2 de Código penal la privación del derecho a la tenencia y porte de armas. ${ }^{\mathrm{I2}}$

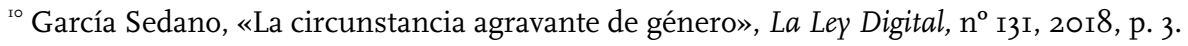

${ }^{\text {II }}$ Romeo Casabona, Sola Reche, Boldova Pasamar, Derecho Penal. Parte General. Introducción. Teoría Jurídica del Derecho, Granada, Comares, 2016, pp. 326-327.

${ }^{\mathrm{r} 2}$ (I7I.4, y 5 CP), 4. El que de modo leve amenace a quien sea o haya sido su esposa, o mujer que esté o haya estado ligada a él por una análoga relación de afectividad aun sin convivencia, será castigado con la pena de prisión de seis meses a un año o de trabajos en beneficio de la comunidad de treinta y uno a ochenta días y, en todo caso, privación del derecho a la tenencia y porte de armas de un año y un día a tres años, así como, cuando el Juez o Tribunal lo estime adecuado al interés del menor o persona con discapacidad necesitada de especial protección, inhabilitación especial para el ejercicio de la patria potestad, tutela, curatela, guarda o acogimiento hasta cinco años. Igual pena se impondrá al que de modo leve amenace a una persona especialmente vulnerable que conviva con el autor. 5. El que de modo leve amenace con armas $u$ otros instrumentos peligrosos a alguna
} 
En el caso de las coacciones está previsto para el supuesto de coacciones leves, en los casos de violencia de género ${ }^{\mathrm{r}}$.

La regulación muestra una contradicción en el sentido de que se establece la pena de privación de derechos en los tipos atenuados de las amenazas y de las coacciones y no esté previsto para el tipo genérico. Por lo que se estima necesaria una reforma en el sentido de unificar la aplicación de la pena de privación del derecho a la tenencia y porte de armas en todos los tipos.

Medida 115- Utilizar la medida de libertad vigilada sobre el maltratador en los momentos en que la víctima se encuentra más desprotegida, como cuando se dicta sentencia condenatoria y aún no se ha ejecutado dicha sentencia, y el agresor ya ha cumplido la pena de alejamiento durante el proceso.

El Código penal regula la libertad vigilada como una medida de seguridad no privativa de libertad, consistente en el sometimiento del condenado a control judicial a través de cumplimiento por su parte de alguna o algunas de las medidas que se establecen en el art. ro6 Cp.

La novedad fundamental que incorpora la medida de libertad vigilada es que resulta aplicable cuando la peligrosidad deriva del específico pronóstico del sujeto imputable en relación con la naturaleza del hecho cometido, siempre y cuando el propio legislador lo haya previsto de manera expresa ${ }^{\mathrm{I}}$.

No se justifica en este caso una modificación legislativa, dado que se está intentando dar solución a una situación procesal concreta, a través de una herramienta con una naturaleza jurídica inspirada, como hemos analizado anteriormente en la peligrosidad del autor. Habría que añadir además las deficiencias de dicha figura, en cuanto a la previsión de un agente de libertad vigilada encargado del control y supervisión de las obligaciones y prohibiciones impuestas, así como de acompañar a la resocialización del sometido a la medida ${ }^{\mathrm{IS}}$.

de las personas a las que se refiere el artículo i73.2, exceptuadas las contempladas en el apartado anterior de este artículo, será castigado con la pena de prisión de tres meses a un año o trabajos en beneficio de la comunidad de treinta y uno a ochenta días y, en todo caso, privación del derecho a la tenencia y porte de armas de uno a tres años, así como, cuando el Juez o Tribunal lo estime adecuado al interés del menor o persona con discapacidad necesitada de especial protección, inhabilitación especial para el ejercicio de la patria potestad, tutela, curatela, guarda o acogimiento por tiempo de seis meses a tres años. Se impondrán las penas previstas en los apartados 4 y 5, en su mitad superior cuando el delito se perpetre en presencia de menores, o tenga lugar en el domicilio común o en el domicilio de la víctima, o se realice quebrantando una pena de las contempladas en el artículo 48 de este Código o una medida cautelar o de seguridad de la misma naturaleza.

${ }^{13}$ (I72.2 CP) 2. El que de modo leve coaccione a quien sea o haya sido su esposa, o mujer que esté o haya estado ligada a él por una análoga relación de afectividad, aun sin convivencia, será castigado con la pena de prisión de seis meses a un año o de trabajos en beneficio de la comunidad de treinta y uno a ochenta días y, en todo caso, privación del derecho a la tenencia y porte de armas de un año y un día a tres años, así como, cuando el Juez o Tribunal lo estime adecuado al interés del menor o persona con discapacidad necesitada de especial protección, inhabilitación especial para el ejercicio de la patria potestad, tutela, curatela, guarda o acogimiento hasta cinco años.

${ }^{14}$ Vázquez González, «Consideraciones político-criminales sobre la nueva medida de libertad vigilada», Revista Jurídica de la Universidad Autónoma de Madrid, n²5, 2012-I, pp. I89-210.

${ }^{15}$ En relación a esta idea acerca de la libertad vigilada puede consultarse Quintero Olivares, Comentario a la reforma de 2015, Cizur Menor, Thomson Reuters Aranzadi, 20I5, pp. 2II-2I2. 
Medida 116- Extender la libertad vigilada a los restantes delitos en el ámbito de la violencia de género.

Manteniendo la argumentación anterior, y teniendo en cuenta que la LO I/I5 de 30 de marzo, amplía el ámbito de la medida de libertad vigilada, de manera que también se podrá imponer en todos los delitos contra la vida, y en los delitos de malos tratos y lesiones cuando se trate de víctimas de violencia de género y doméstica, tal y como se dispone en los arts. I40 bis, 156 ter, y I73.2 CP, introducidos por dicha Ley; no parece prudente hacerlo extensible a otros tipos delictivos que en materia de violencia de género que únicamente por descarte harían referencia a delitos leves.

Medida 127- Programas de Reeducación en Violencia de Género y delitos sexuales.

- Implantación en todo el territorio nacional de programas de reeducación en delitos cometidos contra la mujer. Asegurar que existen suficientes programas de rehabilitación enmarcados en la perspectiva de género.

- Se propone la reforma del Art. 83.2 del Código Penal para introducir la reeducación en los casos de Violencia de Género y delitos contra la libertad sexual, dado el alto grado de reincidencia que se observa en estos tipos penales.

- Posibilidad de crear Unidades o Servicios comunes de coordinación procesal en las Audiencias Provinciales, en coordinación con los servicios de gestión de penas y medidas alternativas de la Administración penitenciaria.

- Establecer que la sustitución o suspensión de la pena de prisión por trabajos en beneficio de la comunidad estén condicionadas a la realización de un trabajo psicopedagógico en relación con el delito cometido (puede ser similar al programa Taseval -«Talleres de Seguridad Vial»).

- Asegurar que todas las entidades que trabajen con agresores acrediten formación en perspectiva de género. Y que los programas de reeducación conlleven una evaluación exhaustiva del impacto del tratamiento sobre el agresor

El art.83 prevé en su apartado 2:

Cuando se trate de delitos cometidos sobre la mujer por quien sea o haya sido su cónyuge, o por quien esté o haya estado ligado a ella por una relación similar de afectividad, aun sin convivencia, se impondrán siempre las prohibiciones y deberes indicados en las reglas $\mathrm{I}^{\mathrm{a}}, 4{ }^{\mathrm{a}}$ y 6. a del apartado anterior.

En el apartado I de mismo precepto establece: 6. ${ }^{a}$ Participar en programas formativos, laborales, culturales, de educación vial, sexual, de defensa del medio ambiente, de protección de los animales, de igualdad de trato $y$ no discriminación, $y$ otros similares.

En este sentido la reforma de 2015 dota de mayor coherencia y agilidad al sistema de control de cumplimiento de estas medidas, al residenciar exclusivamente en los servicios de 
gestión de penas y medidas alternativas de la Administración penitenciaria la vigilancia e información al Juez de los deberes que exijan cierta planificación y gestión ${ }^{\mathrm{r} 6}$.

Más que una reforma legislativa de este precepto lo que se intuye es la necesidad de dar un contenido real al precepto y una puesta en marcha de este tipo de programas de carácter sistemático, para que el juez pueda valorar la revocación de la suspensión de la pena privativa de libertad acordada, en base a su incumplimiento.

\section{C) Tercer grupo: Medidas relativas al delito de quebrantamiento}

Medida 118- Excluir la relevancia del consentimiento de la víctima en la valoración de los casos de quebrantamiento de condena o medida cautelar, sin perjuicio de los posibles efectos sobre la culpabilidad del acusado.

Ha sido muy debatido en la doctrina y en la jurisprudencia el consentimiento de la víctima en el delito de quebrantamiento en el ámbito de la violencia de género. Parece ya indiscutible y superado el hecho de no imputar este delito a la víctima en calidad de inductora o de cooperadora necesaria.

Sin embargo, se establece una distinción en cuanto a la irrelevancia en el consentimiento de las penas privativas de derechos, que no puede quedar al arbitrio de la voluntad de un sujeto privado; dándose relevancia al consentimiento de la mujer cuando se esté ante una medida cautelar ${ }^{\text {r7 }}$.

El Acuerdo del Pleno no Jurisdiccional de la Sala Segunda del Tribunal Supremo de fecha 25 de noviembre de 2008 , recoge expresamente que el consentimiento de la mujer no excluye la punibilidad a efectos del art. $468 \mathrm{CP}$, lo cual será aplicable tanto si hay condena como si hay medida cautelar adoptada judicialmente.

Este criterio que responde a la indisponibilidad por parte de la víctima de la medida cautelar está reforzado por la postura de la Fiscalía General del Estado. Por lo tanto, a todos los efectos ya se está excluyendo la relevancia de dicho consentimiento.

Medida 152- Revisar la aplicación del Art. 40 de la LO 1/2004.

Con la modificación del Art. 468 del C. Penal se considera delito el QUEBRANTAMIENTO de condena, de medida cautelar ... Pero, además, se debe contemplar la posibilidad de establecer, en los supuestos de quebrantamiento, la prohibición de acercamiento o comunicación con la víctima, ya que cuando se dicta la sentencia de condena por el quebrantamiento, puede que ya no esté vigente la medida cautelar o la pena quebrantada en su día. En resumen, reforma del Art. 57.I del Código

\footnotetext{
${ }^{16}$ En relación al sistema administrativo del cumplimiento de las penas se puede consultar: Quintero Olivares, ibídem, pp. I60.

${ }^{17}$ Solé Ramón, «El consentimiento de la víctima de la violencia de género y doméstica y su incidencia en el delito de quebrantamiento de condena y de medida cautelar según la jurisprudencia del Tribunal Supremo», Revista de Derecho UNED, núm. 6, 2010, p. 46r.
} 
Penal para imponer prohibiciones en el caso de comisión de un delito de quebrantamiento del Art. 468 CP.

La justificación de la existencia de penas accesorias por las que, junto a la pena principal, se priva de determinados derechos al condenado puede buscarse en la pérdida de legitimidad para el ejercicio de los mismos por parte de quien resulta condenado en un proceso penal. Sin embargo, un postulado tan general como el anterior resulta inmediatamente objeto de las críticas que tradicionalmente han recaído sobre las penas accesorias en la medida en que la privación de derecho al condenado, de manera automática y cuando el derecho en cuestión no se relaciona con el delito cometido, perjudica su reinserción social y carece de justificación ${ }^{\mathrm{r} 8}$.

Por la propia naturaleza del delito de quebrantamiento el mismo no tiene cabida en la actual redacción del art. 57.1 que lo reserva a

delitos de homicidio, aborto, lesiones, contra la libertad, de torturas y contra la integridad moral, trata de seres humanos, contra la libertad e indemnidad sexuales, la intimidad, el derecho a la propia imagen y la inviolabilidad del domicilio, el honor, el patrimonio y el orden socioeconómico, atendiendo a la gravedad de los hechos o al peligro que el delincuente represente.

Además, hay que añadir que en la mayoría de los casos en los que se comete quebrantamiento, se llevan a cabo otras conductas delictivas que sí tiene cabida en la actual redacción del art. 57.I del Código Penal, como en el caso por ejemplo de amenazas, lesiones y coacciones.

\section{D) Cuarto grupo: Medidas que hacen referencia a delitos concretos dentro de la parte especial del Código penal}

Medida 111- Estudiar la posible modificación del artículo 172ter del Código Penal, que en su actual redacción aprobada en 2015 no cubre conductas como la suplantación de personalidad (salvo para adquirir productos o para hacer anuncios sexuales).

En primer lugar, es necesario aclarar la terminología teniendo en cuenta la confusa redacción de dicha medida, el término jurídico apropiado es identidad y no personalidad.

Es imprescindible diferenciar el concepto de suplantación identidad y usurpación de identidad, ya que solo en el segundo caso se está refiriendo a un tipo delictivo, más concretamente al del art. 40I del código Penal.

Es muy probable que esta medida esté pensada para los casos de creación de cuentas falsas en redes sociales, que ya en la reforma del 2015 el legislador decidió que no tenía cabida como tipo penal, salvo que la conducta fuera más allá y encajase en el tipo de la usurpación (art. 40 I Cp) o como delito contra la intimidad (art. I97 Código penal).

\footnotetext{
${ }^{18}$ Respecto de las penas accesorias y su relación con la función de reinserción social, se puede consultar: Muñoz Conde y García Arán, op. cit., p. 558.
} 
Al margen de los supuestos anteriores el art.I72 ter.3. cubre el supuesto en que se anuncian servicios de naturaleza sexual supuestamente ofrecidos por la víctima, publicando sus datos para que posibles interesados en contratarlos contacten con ella ${ }^{\text {19 }}$, cuando hace mención a la conducta de «...mediante el uso indebido de sus datos personales, adquiera productos o mercancías, o contrate servicios, o haga que terceras personas se pongan en contacto con ella».

Por todo lo anteriormente mencionado, se hace innecesaria una reforma legislativa en este sentido, habida cuenta de la decisión en firme del legislador de no sancionar penalmente la suplantación de identidad.

Medida 112- No considerar las injurias y calumnias a través de las redes sociales en el ámbito de la violencia de género como únicamente un delito leve.

En necesario poner de manifiesto que la forma de cometer el delito no debe cambiar la clasificación del mismo, será el juez quien valore en su caso si las injurias tienen carácter grave (art.208 Cp) o leve (art. I73.4 Cp). No se entiende la referencia a la calumnia leve, inexistente desde la $\mathrm{LO}$ I/20I5, de 30 de marzo.

Medida 113- Incluir en la redacción del artículo 184 del Código Penal, una circunstancia específica en los delitos de acoso sexual, que debería contemplar el móvil de actuar por razones de género, atentando gravemente contra la dignidad de la mujer.

Valga aquí lo apuntado para la medida anteriormente analizada (Medida I28), atendiendo a lo anteriormente expuesto, cabe la aplicación de la agravante del art.22.4, siempre que quede probado dicha manifestación de desigualdad que supere el ámbito de la protección de la indemnidad sexual, por lo que se descartaría la aplicación sistemática de la misma en los delitos anteriores.

\section{Conclusiones}

A lo largo de este trabajo, se ha llevado a cabo un análisis de las medidas propuestas en el Pacto de Estado contra la Violencia de Género, que implican una modificación legal penal, siguiendo la clasificación elaborada en base a la materia propuesta en cada medida.

Respecto del primer grupo, que recoge las propuestas relativas a las circunstancias modificativas de la responsabilidad penal, valoro totalmente inapropiado la desaparición tanto de la atenuante de confesión como la de reparación para los delitos relativos a la violencia de género, si bien se estima pertinente un abandono de la aplicación sistemática de las mismas, para promover una reflexión acerca de su aplicación en este tipo de delitos. En relación a la aplicación de la agravante del art.22.4 del Cp en el delito relativo a la mutilación genital femenina, no parece apropiada la aplicación de agravante genérica en este caso, si bien cabría estudiar la implementación de circunstancias agravantes especificas atendiendo a una mayor lesividad de la que recogería el tipo básico. Distinta es la

\footnotetext{
${ }^{19}$ Quintero Olivares, op. cit., p. 387.
} 
conclusión en relación a la medida que recoge la necesidad de aplicar esta misma agravante respecto de los delitos recogidos en los art.I78 a I83 bis del Código Penal, respecto de los que sí cabria la misma siempre que quede probado dicha manifestación de desigualdad que supere el ámbito de la protección de la indemnidad sexual. En relación a la agravante de reincidencia, cabría valorar la posibilidad de modificar el artículo 22.8 del Código penal, posibilitando la aplicación de la agravante en los delitos de misma naturaleza, independientemente de la ubicación que ocupen en la norma, argumentando la similitud del bien jurídico protegido, lo cual requeriría de una reflexión previa y extender el debate acerca de la constitucionalidad no solo del precepto, que ya existe doctrinalmente, sino de la futura modificación del mismo en este sentido.

El segundo grupo recoge propuestas en relación a algunas de las penas y medidas recogidas en la norma penal. La propuesta de extender la pena accesoria de privación del derecho a la tenencia y porte de armas a los delitos de amenazas y coacciones no resulta incongruente teniendo en cuenta la contradicción en el sentido de que se establece la pena de privación de derechos en los tipos atenuados de las amenazas y de las coacciones y no esté previsto para el tipo genérico. Respecto a la medida que propone la aplicación de la libertad vigilada para un determinado momento procesal, en el que se entiende que la víctima está más desprotegida, no se justifica en este caso una modificación legislativa, dado de se está intentando dar solución a una situación procesal concreta, a través de una herramienta con una naturaleza jurídica inspirada en la peligrosidad del autor. Para estos casos habrá que buscar una solución a través de medidas de carácter administrativo. Se propone además que se extienda esta medida a todos los delitos relacionados con la violencia de género, teniendo en cuenta que la LO I/I5 de 30 de marzo amplía el ámbito de la medida de libertad vigilada, de manera que también se podrá imponer en todos los delitos contra la vida, y en los delitos de malos tratos y lesiones cuando se trate de víctimas de violencia de género y doméstica, no parece apropiada una reforma en este sentido. En cuanto a la medida relativa a Programas de Reeducación en Violencia de Género y delitos sexuales, más que una reforma legislativa lo que se intuye es la necesidad de dar un contenido real al precepto y una puesta en marcha de este tipo de programas de carácter sistemático, para que el juez pueda valorar la revocación de la suspensión de la pena privativa de libertad acordada, en base a su incumplimiento.

El tercer grupo recoge medidas relativas al delito quebrantamiento En este sentido se reclama la exclusión de la relevancia del consentimiento de la víctima, que ya se está contemplado. Se solicita contemplar la posibilidad de establecer, en los supuestos de quebrantamiento, la prohibición de acercamiento o comunicación con la víctima, algo que no se sostiene teniendo en cuenta la naturaleza del delito, que además se pretende justificar una situación procesal concreta de desprotección de la víctima.

Dentro del cuarto y último grupo se hace referencia a medidas que proponen modificar preceptos contenidos en la parte especial del código penal. Se propone la posible modificación del artículo I72ter del Código Penal, con la finalidad de penalizar conductas que ya están contempladas en otros preceptos de código. Parece que tampoco tiene mucho sentido una modificación en el Código penal para no contemplar las calumnias e injurias a través de las redes sociales como delito leve, tal y como se propone en la medida, teniendo 
en cuenta que independientemente del medio a través del que se realice, será el juez quien valore si aplicar el tipo básico o el tipo atenuado. Respecto a la medida que propone incluir una circunstancia específica de género en el art. ı84, cabe la aplicación de la agravante del art. 22.4, siempre que quede probado dicha manifestación de desigualdad que supere el ámbito de la protección de la indemnidad sexual.

A modo de conclusión, el texto recopila medidas con reformas legislativas que, en la mayoría de los casos, dado lo analizado, no requieren de dicha modificación legal sino de una revisión de estructuras y recursos administrativos y de cierta interpretación judicial de determinados preceptos. Resulta loable el esfuerzo por proponer soluciones a vicisitudes que invaden una problemática tan cruel y real como es la violencia de género, sin embargo, las medidas tienen que apuntar a otros ámbitos de nuestra sociedad. No hay reforma penal en España que no comporte un incremento de penas, como si los poderes públicos necesitaran protegerse frente a posibles críticas de los sectores más represores de nuestra sociedad aumentando y exhibiendo su musculatura punitiva.

\section{Bibliografía}

GARCía Sedano, T. «La circunstancia agravante de género», La Ley Digital, nº I3I, 20I8, pp. I-6.

Muñoz Conde, F.; García Arán, M. Derecho Penal. Parte General. Valencia, Tirant lo Blanch, 2015.

Peramato Martín, T. «Modificaciones en el Código penal, Ley Orgánica I/20I5, de 30 de marzo, en materia de Violencia de Género», Boletín de la Comisión de violencia de género de Jueces para la Democracia, $\mathrm{n}^{\circ}$ 2, 2016.

Quintero Olivares, G., Comentario a la reforma de 2015, Cizur Menor, Thomson Reuters Aranzadi, 2015 .

Romeo Casabona, C.M.; Sola Reche, E., Boldova Pasamar, M.A., Derecho Penal. Parte General. Introducción. Teoría Jurídica del Derecho, Granada, Comares, 20I6.

SolAz SolAZ, E. «La circunstancia atenuante de confesión», La Ley Digital, nº II3,2005, pp. I-I6.

SOLÉ RAMÓN, A.M., «El consentimiento de la víctima de la violencia de género y doméstica y su incidencia en el delito de quebrantamiento de condena y de medida cautelar según la jurisprudencia del Tribunal Supremo», Revista de Derecho UNED, nº 6, 2010, pp. 447-463.

VÁZqueZ GonZÁlez, C. «Consideraciones político-criminales sobre la nueva medida de libertad vigilada», Revista Jurídica de la Universidad Autónoma de Madrid, nº 25, 20I2-I, pp. I98-210.

VillaCAMPA EstiaRTE, C., «Pacto de estado en materia de violencia de género: ¿más de lo mismo? », Revista Electrónica de Ciencia Penal y Criminología, n² 20-04, pp. I-38.

«La circunstancia atenuante de la reparación del daño», Comentario jurídico en La ley penal, $\mathrm{n}^{\circ} 44$, Sección monografías de Jurisprudencia, 2007, pp. I-15. 